\title{
The Changes of Media Landscape in Malaysia: How Citizen Journalism Poses Threats to Traditional Media
}

\author{
MALIA TAIBI \\ TEH YIN NA \\ Universiti Malaysia Sarawak
}

\begin{abstract}
The rise of the Internet and social media have provided alternative ways for people to access information. Communication technologies have given a new platform for ordinary people outside of the journalism profession to become content creators instead of content users. This gives rise to citizen journalism as ordinary people can publish, share, discuss and debate about news and stories in a global sphere with others. While some might view this trend as a positive way of disseminating information, citizen journalism is facing numerous criticism as people are questioning their credibility regarding the news sources and the ethical code of practice that they use when collecting information. This study aims to highlight the changes taking place in the Malaysian media landscape in response to citizen journalism as well as the threats towards mainstream journalism. Data was collected through a qualitative in-depth interview method with five journalists working in the mainstream news organizations in Malaysia. All respondents have vast experience in journalism, both in the traditional newsroom and online news portal settings. The results indicated that changes occurring in the media landscape are due to several reasons namely instant gratification of the news; changed mode of transmission; new styles of news writing; open and freer media environment and change of gatekeeping process. Threats posed by citizen journalism to traditional media are commercial impact, stealing of credits and stiff competition. It was concluded that newsrooms and journalists have to change in order to face the challenges posed by citizen journalism.
\end{abstract}

Keywords: Mainstream media, citizen journalism, media landscape, Internet, threats.

\section{INTRODUCTION}

The advent of communication technology has definitely changed how people consume news and other information. Waiting anxiously for news to be published the next day is a thing of the past. Now, people can get the latest news instantly as the event happens directly from their smartphones and other mobile gadgets as long as they are connected to the Internet. Before the birth of the Internet, most people will be glued in front of their television or listening to the radio to gain insight into breaking news on current issues and happenings. Now, with technology people can even share the news with others in social media platforms that make the dissemination of information becoming more pervasive. Television and radio were considered as elusive, as it provided the only means for people to get public information from outside their private sphere.

With the emergence of modern technology and social media, the phenomenon of "citizen journalism" is very well on the rise. Citizen journalism is the spontaneous creation, dissemination, and evaluation of current happenings by regular citizens and media users using modern technology, instead of reporting by a professional reporter. Nowadays, citizen journalists have become regular contributors to current news, reporting information and sharing some of today's most iconic images, especially where professional journalists have limited access or none at all (Jurrat, 2011). 
Social media has exploded to become an important and ubiquitous communication platform for social networking and content sharing over the years (Asur \& Huberman, 2010). This has transformed the advent of "journalism" in that it is no longer a one-way and topdown communication whereby journalists directly "feed" readers with information. Nowadays, citizens also play the role of journalists rather than a merely passive consumer of news. Inevitably, journalists are prompted to incorporate the modern formula of news production, as they shift to keep up with the threats and challenges citizen journalism pose towards them. Thus, this paper aims to explore the changes that take place in the traditional media as citizen journalists are slowly taking the role of traditional journalists in reporting the news to the masses. At the same time, this paper also will examine the threats posed by citizen journalists that definitely have impacted the media landscape in Malaysia.

\section{LITERATURE REVIEW}

The social media age has produced a culture whereby everyone could now, in some form, be journalists in their own right. Citizen journalism has and still is growing to become increasingly prominent in contemporary media, further redefining the traditional journalistic roles, values and practices. The ability to access news and information at one's fingertips is key, raising concerns among newspapers and broadcasting industries that citizen journalism will come to replace professional and mainstream journalism. Especially in this current social media age, the influence of citizen-generated news on society is profound. As this form of "participatory" journalism seems to add another dimension that questions previous boundaries alongside definitions of professional journalism, the borderline that separates professional journalists and their audience is seemingly blurring (Domingo et al., 2008).

Traditionally, journalism has been attached to the institution of the media, based on the production of news by dedicated paid labour - the journalists (Domingo et al., 2008). In the contemporary decade, however, new communication technologies, particularly networked communication, have made it possible for just about anyone to publish content for a potentially global audience (Domingo et al., 2008). However, in most cases, citizen journalists are not trained and, some may argue, lack the understanding of basic rules of good journalism. Despite long-standing issues of credibility and professionalism in citizen-based online news, mainstream journalism is struggling to contest the ever-growing prominence of citizen journalism. According to the survey by the Malaysian Communications and Multimedia Commission (2017), Internet penetration is already at 76.9\%, with 24.5 million Internet users in Malaysia. A more recent report by Alias (2018) in the New Straits Times noted that Internet penetration in Malaysian has increased to 85.7 percent in 2018. Additionally, a bulk of Internet users' mainstream Internet activity in Malaysia is social networking sites with 86.3 percent (Alias, 2018). Indeed, more Malaysians are seen to be shifting towards the online platform as their medium of choice for convenient reading and immediate information including amusing, complex, opinionated and even political news.

Citizen journalism these days largely means a more two-way, engaging and reciprocal relationship between the news producer and consumer. The "participatory" culture is attractive, opening up doors previously unknown to news consumers in Malaysia, especially in such a constrained mainstream media landscape. Journalism, in this era of interactive communication technologies, is proclaimed to be "dead" and called a "zombie institution" (Deuze, 2006, p. 2 as cited in Wahl-Jorgensen \& Hanitzsch, 2009). New forms of participatory journalism have challenged the authority of conventional journalism, whereby the latter now faces immense pressure in order to remain relevant. The existence of alternative means for 
publishing and consumption of news means that mainstream journalism may no longer monopolize the news landscape in modern society. Instead, they now have to accommodate other platforms that play similar roles in news production. This raises the question of whether mainstream news organization is able to evade their seemingly bleak fate with some reinventions down the line, or whether citizen journalism will ultimately bring them to be obsolete. Hence, this matter must be delved into further $t$ to understand the profoundness of citizen journalism and gain a richer insight into the future prospects and direction of mainstream journalism.

Contemporary literature studying journalism and the changing media landscape had on many occasions pointed out that instant gratification of news has been made possible. As noted by Peters (2015), the news is increasingly mobile, instantaneous and available "on demand." The world full of citizen journalists means that convenient updates are not just the norm but an expectation (Peters, 2015). With technological advances, the means to access "news" at any moment without much hassle likely changes the experience of journalism for many people (Peters, 2015). A study by Kirby-Petruccio (2017) expressed that with constant notifications being sent to phones and trending topics on Twitter and Facebook, digital users of today can now be up-to-date with issues elsewhere in the world within a matter of seconds. This means that media consumers now have the privilege of instant gratification to news and information that transcends boundaries with just a click away. The rapid technological development has provided a lot of conveniences for citizens to spread their news.

In the context of Malaysia itself, Shivadas and Krishnamoorthy (2004) supported this view, noting that the convenient access to high speed Internet has prompted and popularized the delivery of broadcast quality audio and video. Breaking news is posted as soon as an incident occurs (Shivadas \& Krishnamoorthy, 2004). Indeed, citizen-generated news has been quick to go widespread online, including in Malaysia. As Kirby-Petruccio (2017) stated, this scenario marks a notable shift from the mainstream media landscape that dominated before the introduction of social media, where consumers had to wait until the evening news to receive the headlines. Messages posted and shared by citizen journalists on social media has the ability to go viral in a short time, transcending boundaries to reach a global and interconnected audience.

\section{METHODOLOGY}

This study employed a qualitative method. Qualitative method is widely used in social science research which aims at a comprehensive and interpreted understanding of the social world of research participants by learning about their social and material circumstances, their experiences, perspectives and histories, as stated by Ritchie and Lewis (2003). The study of journalism, whether citizen-based or mainstream news, involves media and society, both of which often go hand-in-hand. This correlation between media and social beings requires that an in-depth nature of research be carried out to achieve a better understanding of the phenomenon to be explored. The study of citizen journalism, the transformed media landscape and threats towards mainstream journalism could be looked into far beyond its surface level through qualitative methods. That being said, a qualitative approach to conducting social science research is particularly good as it addresses research questions that require a more detailed explanation or understanding of social phenomena and their contexts (Ritchie \& Lewis, 2003). 
Data was collected using an in-depth interview with five journalists working in the mainstream media. Interviews have a long and rich history as a methodological tool for better sense-making of social actors, drawing out the rhetorical construction of their experiences and perspectives (Lindlof \& Taylor, 2002 as cited in Lewis, Kaufhold \& Lasorsa, 2010).

\section{RESULTS AND DISCUSSION}

As mentioned earlier, data was collected from five respondents from four different print media organizations in Malaysia. Four of the journalists work in the newspaper industry whereas one respondent works for an online news portal but with some years of experience working in the print media. Two of the respondents have over 20 years of experience working in the mainstream media and hold the post of chief editors in their respective organizations. Another respondent has been working in the mainstream media for 18 years and the remaining two respondents had started their career as journalists in their current respective organizations for a total of 8 years. The respondents fall between the ages range of 30 and 60. The majority of them possess a higher education background in fields related to journalism, with one having completed a Doctor of Philosophy in Journalism, two had a Bachelor's Degree in Communication, one respondent with a Bachelor's Degree in Hospitality, while another respondent held a Diploma in Mass Communication. From the interview with the respondents, few emerging themes cropped up when discussing how citizen journalism is transforming the media landscape in Malaysia.

\section{Changes in Media Landscape in Malaysia}

i. Instant gratification of news

All of the respondents agreed that the fast-paced nature of the Internet and the social media platform allow users to post and share not only news but visual footage as well. Citizen journalism was stated to be a by-product of the change of technology, a derivative of technological advancements from the old to the modern days. Thus, the avenue for sharing information on the social media platforms gave birth to the instant gratification of news among citizen journalists to constantly update post or share information and news to other users. As noted by some of the respondents:

"Before that, during the 1990s even, everyone can also be a reporter, but it is more informal, just by word of mouth to the reporter, that is reporting, he is reporting to me, so I will go to the scene, but now instead of that, he will do the report himself through his social media. So it's because of the change of technology that created citizen journalism, the by-product."- Respondent 1

"I think people are obsessed about who share the information first and the Internet is there to provide them with the platform. This gives birth to "instant gratification of news" among citizen journalism as is much faster, "on-thespot" and always "one-step ahead" of traditional journalism. - Respondent 4

Similarly, as noted by Respondent 5, nowadays everything is happening in a fast-paced environment. Instead of relying on newspapers, which are comparatively much slower, videos found online could be used as a reference for citizens to get the gist of current happenings. 
"It's up-to-date, very fast and free. It's easy, with its accessibility just using the smart phone. They don't have to wait for the next morning for news, they can also refer to videos now, and can make comments if they want to." Respondent 5

\section{ii. Changed mode of transmission}

The technology has definitely plays a pertinent role in how information is being disseminated to the masses. This is very much to the advantage of citizen journalism where the mode of transmission of news has changed from purely traditional to navigating news online. The world full of citizen journalists now means that traditional journalism industries have to avert their focus and depart from regular habits of reporting. It was recalled by some respondents that journalists previously relied on the computer to write articles, and now it is all changing to the smart phone - which is a significant shift from traditional ways. It appears that the versatility to navigate between both print and online is deemed to be an important trait that journalists must possess.

"I think the competition is heating up as news stories have to report from various angles; one online, one live and one for print in order to get the attention of our readers. Journalists must be able to do multitasking jobs or otherwise, citizen journalist who happens to be on the scene can post his report on the social media platform, beating us to it." - Respondent 4

The current media landscape is changing and the dynamic nature of it means that it is now vital to reach netizens' expectations so journalists have to be ready to do online reporting as well as "video-on-the-scene", as mentioned by a Respondent 4. The importance of having the traditional media embrace and focus on the digital and technological side was widely acknowledged. Most respondents advocated the crucial need to constantly change and adapt as a result of the current media landscape, and that it will be impossible for newspapers to only remain with physical copies. Instead, they had to venture into online reporting as well to cope with current trends, which is indicative of the booming of the online news portal.

"It's changed the mode of transmission for newspapers from traditional newspaper papers to online papers, but now, media portals have to fill the other avenues as well, so they also got social media, and they will transmit through Twitter and even Instagram nowadays." - Respondent 3

The respondent also talked about the difference in the method of transmission between traditional and citizen journalists - traditional has the infrastructure for mass transmissions like newspapers and a well-maintained website nowadays, while citizen journalists generally use free or low-cost tools such as existing social media sites - Tumblr and Twitter - or semi-paid websites such as Blogpost. Hence, it is worth noting that social media platforms are emerging to be top sources for the spreading of information in this current age. 
"The media have to change the way they operate and work, including the newsroom. The reporters, the journalists, have to multitask, not only writing news for the print media but also for the online media, the portals. They need to know how to take videos and write very fast, not only using the laptop but they are using this now, the smart phone, it's everything. They also need to hold on to various skills and be technology-savvy, otherwise they will be outdated." - Respondent 5

This amplifies the need for newsrooms now have to revamp the way they operate and depart from traditional norms, navigating both print and online. Speed is becoming ever more important and traditional forms of journalism are prompted to change or they would face the risk of being side-lined.

\section{iii. New style of news writing}

Citizen journalism has driven the need for traditional journalism to adopt a new approach towards news writing to cater to the needs and demands of media consumers worldwide. As more content is being pushed out by citizen journalists at any given time, they are also seen as responsible for creating a new style of writing. This trend is forcing traditional journalism to embrace the new style of news writing as most mainstream media are producing the online news version of the printed newspapers.

"Take for example one issue, many people are commenting on it and it makes it easier for us to see the different viewpoints. We can put it as a story by itself. But we have to stay alert because it keeps on changing, the dynamic is crazy." - Respondent 1

Respondent 1 mentioned this phenomenon means that citizen journalism is being used as a source and an outlet for tips for real-time information. In this case, he stated that citizen reporting could be viewed in a positive light because the information can be utilized to their (traditional journalism) advantage as they see them beyond mere threats. On the contrary, citizen journalism is seen more as an outlet for tips about breaking news and current happenings everywhere in the world. It thereby created a new style of writing for traditional journalism institutions to use social media as a source. He explained further that the dynamics of citizen reporting means that the traditional media now want to use that situation as an advantage, resting on the fact that they are still bound to the rules and ethics of the media.

"People will realize that and go to traditional media as confirmation. They will just read and take notes of whatever comes across (on social media) but for verification, they will go to traditional media for verification. So it is used as an advantage for us. It is just a matter of hits and trust." - Respondent 1

Citizen journalism is also viewed as an important source of information in the current media landscape. Respondent 4 pointed out that citizen journalism sometimes acts as important providers for news, tips and information, all of which help them in curating a story or a piece of news article. Respondent 2 also acknowledged that the style of writing has also changed with current media consumers and readers' interests at heart. 
"We have to also refer to what netizens like, what news that would attract attention, and then we change the angle from there, such as for political news, we try not to report just from facts or mere reporting, but we have to see what readers want and demand." - Respondent 2

Respondent 1 concurred with the above statement as more stories about reactions are favourable to suit readers' interests.

"Normally the same stories that we will put up for print the next day, we will first put it online, probably from a different angle or a shorter version, and we see the reactions from the "hits". Then in the afternoon around $4 \mathrm{pm}$, we will have a presentation from our colleagues in the online news department. We take note of the 'hot' stories and determine those to publish in newspaper the next day." - Respondent 1

This is indicative of how citizen journalism is forcing traditional newspapers to be more selective in choosing the "news that really matters" to be published - ones that could attract the attention of readers. The ability of citizen journalists to garner attention and 'hits' among readers also means that newspapers have to focus more on writing news to satisfy the reader's interests.

"This form of reporting is driven by popularity and public opinion where the media now are forced to chase hits. Hence, a new form of reports is emerging that feeds on "sensationalism", instead of more serious and breaking news." - Respondent 5

"Since the news written by citizen journalists is meant for the people, they have the most direct idea of what people want to read and traditional journalists might not have the same opinions with the public sometime." Respondent 4

Despite citizen journalists are not trained as professionals, the respondent noted that members of the public still reads them and believe them. The appealing factor lies in the juiciness of the kind of news written by citizen journalists. Hence, traditional journalists have to change their angle of reporting while not compromising journalism ethics and principles.

iv. Open and freer media environment

There is also deemed to be a "deregulation of media propagation" happening in the contemporary media landscape, as stated by Respondent 3. Established news organization including the mainstream media are part of a formalized organization with regulated structures. Citizen journalism, however, usually operates freely.

"Last time, you need a newspaper license in order to print a newspaper. With the Internet, you can write anything without having to get a license and this has given birth to citizen journalism." - Respondent 3 
Citizen journalism embodies the entire sense of how journalism these days tend to be freer and more open. Mainly due to the Internet, the public is able to reveal almost everything. The ease of accessibility of the Internet and social media, citizens can publish news on-the-spot without much hassle and without following procedures. The open media environment means that consumers are no longer passive but interactive, the news is no longer one-sided but now comes in both ways. Active media consumers are now presented with a platform to make comments and offer their ideas, opinions and viewpoints expressing their agreements or disagreements.

\section{v. Change of gate keeping process}

As citizen journalism is gaining more foothold in influencing the news agenda, it alters the level of gate keeping where professionals once had total control over. Most of the respondents identified that citizens now also play a role in influencing - directly or indirectly - the content being pushed out to audiences. While the mainstream media like newspapers and television, power mostly falls into the hand of the government or media owners but in social media, it is controlled by citizens because "it is their hub to share content." The multidimensional nature of gate keeping in the media landscape was further acknowledged by other respondents. One respondent stated there is now multiple gatekeepers.

"The main factor will be popularity, which is driven by public opinion. Everyone has to chase hits. Secondly, there are news sources - these are people who choose to share information, so that's an advantage for a formal media organization. You have direct access to news sources like industry leaders, or politicians who want to make an official statement. Only formal media can have access to that - but if they choose not to comment then there can't be a news story later. Within organization, there is upper management so the editors or say, advertising controls, and tied directly to that of its private parties. But now more than before, public opinion has more influence." - Respondent 3

Addressing the reality that journalists now shoulder a lot of work and are required to be versatile, gatekeepers are to acknowledge this fact in order to draw in readers. It is considered important to understand the function of the Internet in the mainstream newspaper, and what the readers want. However, there are other pressing factors to be put into contemplation. Mainstream journalism still assumes great responsibility to consider the ethics and sensitivity of certain issues before publishing news.

"We have to think twice and we have to check the facts. We thought that the public will like it (the news) but again, what if it touches on sensitive issues? We still have code of ethics to hold on to." - Respondent 1

Different parties determine the news agenda in a different medium. If it is the traditional media, the gatekeepers are still the owners of the media organizations which include the owners, board members, chief editors, editors and the like. As for online, those who finance the portal or "admins" of a certain website have the authority to control the news. On the contrary, it was acknowledged by some of the respondents that citizens themselves are autonomous over the news nowadays - the main gatekeepers in the 
contemporary media landscape. This is because citizen journalism is more dynamic, mostly due to the Internet and they are able to reveal everything. Besides, it is also due to the public perception that citizen journalists are reliable and "on-the-spot." One respondent mentioned that editors have less control now because reliance also falls to other people including an advertiser, and they cannot afford to lose advertising. It is not anymore characterized as oneway gate keeping, but pointing more towards "gate-watching" instead. As mentioned by Respondent 5:

"Wrong facts can be fast to generate negative comments. The advantage of advances in technology is that news can be amended and updated, but at the same time it is still risky and can cause a serious problem."

\section{Threats Towards Mainstream Journalism in Malaysia}

Based on the in depth interview with the journalists, a number of threats have been identified caused by citizen journalism that has affected mainstream journalism.

\section{i. Commercial impact}

Citizen journalism gives rise to more alternative platforms where media consumers are able to obtain information. Majority of the respondents agreed that the trend is leading towards an overall commercial impact to mainstream media. As noted by Respondent 1 :

"Newspaper industry is entering its sunset era because people are not reading it anymore. We cannot depend on the sales of the newspaper because people are looking elsewhere for news. This is affecting the circulation and advertising team as well because advertisers won't place advertisements anymore because of the dwindling number of readers."

It was also mentioned by the respondents that newspapers are losing readership because of citizen journalism websites that tend to link the news from the official online newspaper and garner more viewers through "shares" and "hits." This directly affects the sales of the newspaper and also translates into the drop in advertising revenue. Subsequently, the loss of income from advertising revenue largely threatens the entire commercial and financial well-being of the media organization because they largely depend on advertising as their main source of revenue. This sentiment was echoed by the following respondents:

"Generally speaking, the newspaper industry is heading for a downturn, because of the social media platform where it becomes the platform for citizen journalism to flourish."- Respondent 2

"The advertising revenue affected our operation. That's why a lot of media companies are offering a Voluntary Separation Scheme (VSS) to their staff because they cannot afford to pay their salaries." - Respondent 5

ii. Stealing of credit

Another common threat towards traditional journalism stated by the majority of respondents is the stealing of news and credit. Citizen journalists were coined as "thieves", stealing news 
and information resources from established and authentic media and passing it off seemingly as their original piece of work. Even so, lack of credit is being averted to the mainstream media which are the original source of information. As mentioned by respondents below:

"For example, a crime story. If they (citizen journalists) happen to be at the scene, they will get the same news that is being covered by the mainstream journalists. Mainstream media practitioners have the resources and have established good contact with the police and other enforcement agencies. What we noticed was they (citizen journalists) usually get the information from the various newspapers and re-write the news. We call that "curi" (stealing). - Respondent 1

"In a way, all the hard work by traditional journalists go unappreciated citizen's journalists appeared to be "active" and seem more "superior" at reporting news, but it is the "real" reporters are the ones who are the one who is doing the actual work." - Respondent 1

"Citizen journalism portals involve a lot of plagiarism - whether they take a piece from a news or the whole story. Their readers do not bother to read the byline, so the public's lack of care for credit is affecting the recognition and effort by the journalists to produce the story. - Respondent 3

The current media landscape is also pictured by the respondents as a battle between keyboard warriors and journalists. The real journalists do their job by attending functions and write their story which they put great effort and time. Bloggers, however, are more prone to stealing news by rewriting the information found in other platforms and publishing the story as if their own. This definitely can demoralize the journalists because it takes away their effort and hard work of going to the scene to cover the news.

\section{iii. Stiff competition}

Following the rise of citizen journalism, all respondents expressed their opinions that the media landscape is becoming increasingly competitive for professionals. In particular, the words "challenge", "challenging" or "competition" appeared more than 5 times during the interview with each respondent. The competition of "who gets the first say" is coming into play among citizens and traditional journalists as a form of competition who can produce the news faster. Most of the respondents acknowledged the challenge between traditional and new media is that "everyone wants to be a reporter nowadays". Similarly, speed is considered as more crucial than ever, justifying how mainstream media now reports breaking news in as brief as one or two paragraphs first only to be followed up later.

This was expressed by Respondent 4 that there is no significant competition in the journalism industry, whereby traditional news media operating online (news portals) have to pick up their pace, or they may risk losing out to citizen journalists.

"Because of this online thing, the moment we finish a function, we give ourselves a deadline, you must pump in the story within one hour and then let the editor, edit and upload it to the system." - Respondent 4 
Traditional journalism is said to be significantly disadvantaged because newspapers are falling behind in terms of time or pace of news transmission. Citizen journalists have the upper-hand where it is possible for them to conveniently write and post "on-the-spot", with a general picture of breaking events albeit with questionable depth and accuracy of reporting. The Internet is utilized to share information in a timely manner although citizen journalists tend to be "passers-by" or "eye-witnesses" with a view of events on a mere surface level. This is totally in contrast to traditional journalists who have to go through procedures and proper journalism standard practices to ensure any news published is as accurate as possible.

Addressing this competition, majority of the respondents acknowledged that the job scope for traditional media has widened and journalists have to be versatile in performing their duties. They have to accept these changes and "absorb" alongside learning and adapting to social media. Competition is inevitable and tightening in the digital age and this calls for the need of traditional journalists to change their ways of doing things, as well as the ways newsrooms work - adaptation is now vital to survive under such dynamism. Traditional journalists now no longer have a complete monopoly on stories and information in the mainstream media as the do previously.

\section{CONCLUSION}

The Internet and social media, in particular, has challenged the previously existing boundaries that newsrooms have in terms of providing information. It is often considered a more open and unrestrained media environment, to which Suborg (2008 as cited in Chinnasamy, 2015) stated is utilized to enhance participation in a democratic society especially in political communication, and also enhances the information flow and access to communication. This gave rise to the Internet being termed as the "fifth estate," meaning that it acts as a watchdog that monitors the systems and policies on behalf of the people, simultaneously holding the power to influence society.

The Internet is also responsible for the birth of citizen journalism as people are constantly in need to get the latest information all the time. This definitely affected the traditional print media as it could not publish news as fast as the online news portal or other social media platforms. This trend has forced traditional media to change their business strategy by introducing an online version of the newspaper including offering e-paper to their readers who prefer digital format over printed version.

\section{BIODATA}

Malia Taibi is a senior lecturer at University Malaysia Sarawak. She graduated from Universiti Teknologi Mara (UiTM) Shah Alam with a Bachelor of Mass Communication (Journalism) and earned MA in Communication and Media Studies from Coventry University, United Kingdom. Email: tmalia@unimas.my

Teh Yi Na is a student from Communication Studies Program at University Malaysia Sarawak. Email: yinnateh@gmail.com 


\section{REFERENCES}

Alias, A. (2018, March 19). Malaysia's Internet penetration is now 85.7 per cent. New Straits Times. Retrieved from https://www.nst.com.my/business/2018/03/346978/malaysias-internetpenetration-now-857-cent

Asur, S., \& Huberman, B. A. (2010, August). Predicting the future with social media. Paper presented at the meeting of the 2010 IEEE/WIC/ACM International Conference on Web Intelligence and Intelligent Agent Technology, Toronto, Canada. Retrieved from https://arxiv.org/pdf/1003.5699.pdf

Domingo, D., Quandt, T., Heinonen, A., Paulussen, S., Singer, J. \& Vujnovic, M. (2008). Participatory journalism practices in the media and beyond: An international comparative study of initiatives in online newspaper. Journalism Practice, 2(3), 326342. doi: $10.1080 / 17512780802281065$

Jurrrat, N. (2011). Mapping digital media: Citizen journalism and the Internet. London, UK: Open Society Foundation.

Kirby-Petruccio, L. B. L. (2017). Gate keeping or \#porteouverte: Citizen journalism and the digital media landscape (Bachelor's thesis, Utrecht University, Utrecht, Netherlands).

Lewis, S. C., Kaufhold, K., \& Lasorsa, D. L. (2010). Thinking about citizen journalism: The philosophical and practical challenges of user-generated content for community newspapers. Journalism Practice, 4(2), 163-179. doi: 10.1080/1461670090315691

Malaysian Communications and Multimedia Commission. (2017). Internet users survey 2017 (Statistical Brief Number Twenty-One). Retrieved from https://www.mcmc.gov.my/skmmgovmy/media/General/pdf/MCMC-Internet-UsersSurvey-2017.pdf

Peters, C. (2015). Introduction: The places and spaces of news audiences. Journalism Studies, 16(1), 1-11.

Ritchie, J., \& Lewis, J. (2003). Qualitative research practice: A guide for social science students and researchers. London, UK: Sage Publications.

Shivadas, P. C., \& Krishnamoorthy, M. (2004). The you in journalism. Petaling Jaya, Selangor: Silverfish Books.

Wahl-Jorgensen, K., \& Hanitzsch, T. (2009). The handbook of journalism studies. Retrieved from https://keralamediaacademy.org/wp-content/uploads/2015/02/Handbook-ofJournalism-Studies.pdf 